OPEN ACCESS

Edited by: Shaobin Wang

Curtin University, Australia

Reviewed by:

Giovanni Palmisano,

Khalifa University,

United Arab Emirates

Zhou Baoxue,

Shanghai Jiao Tong University, China

*Correspondence:

Qing Su

suqing@gdut.edu.cn

Chunyan LV

ıcy@zihu.edu.cn

Specialty section:

This article was submitted to Catalysis and Photocatalysis,

a section of the journal

Frontiers in Chemistry

Received: 24 April 2019 Accepted: 21 November 2019 Published: 12 December 2019

Citation:

Li Z, LiU G, Su Q, Lv C, Jin X and Wen X (2019) UV-Induced Photodegradation of Naproxen Using

a Nano $\gamma$-FeOOH Composite:

Degradation Kinetics and

Photocatalytic Mechanism.

Front. Chem. 7:847.

doi: 10.3389/fchem.2019.00847

\section{UV-Induced Photodegradation of Naproxen Using a Nano $\gamma$-FeOOH Composite: Degradation Kinetics and Photocatalytic Mechanism}

\author{
Zhanyi Li ${ }^{1}$, Guoguang Liu ${ }^{1}$, Qing Su ${ }^{2 *}$, Chunyan $L^{3 *}$, Xiaoyu $\operatorname{Jin}^{1}$ and Xiaoqing Wen ${ }^{1}$ \\ ${ }^{1}$ School of Environmental Science and Engineering, Guangdong University of Technology, Guangzhou, China, ${ }^{2}$ School of \\ Computer Science and Technology, Guangdong University of Technology, Guangzhou, China, ${ }^{3}$ Department of Materials \\ Chemistry, Huzhou University, Huzhou, China
}

Naproxen (NPX) is one of the most common pharmaceutical and personal care products found in surface water, which is recalcitrant to degradation by biological treatment or complete removal via traditional sewage treatment processes. In this study, nanoscale $\gamma$-FeOOH was synthesized and characterized by $\mathrm{X}$-ray diffraction, scanning electron microscopy, surface analysis, and analysis of the forbidden bandwidth. Under UV irradiation, $\gamma$-FeOOH had the capacity to rapidly photodegrade NPX. The photodegradation rate of NPX was dependent on the concentration of $\gamma-\mathrm{FeOOH}$ in solution, initial NPX concentration, and $\mathrm{pH}$. By increasing the concentration of $\gamma-\mathrm{FeOOH}$, the NPX photodegradation rate was increased and then remained stable. Furthermore, the highest photodegradation rate for NPX was observed under acidic conditions. Through the analysis of the active substances (such as $\mathrm{h}^{+}, \mathrm{e}^{-}, \mathrm{OH},{ }^{1} \mathrm{O}_{2}$, and $\mathrm{O}_{2}^{-}$) by electron spin resonance, the photocatalytic mechanism of NPX degradation on $\gamma$ - $\mathrm{FeOOH}$ was determined to be semiconductor photocatalysis.

Keywords: $\gamma$-FeOOH, NPX, photodegradation, photocatalysis, active substances

\section{INTRODUCTION}

With continuous improvements in anthropogenic living standards, the contamination of natural waterways has become an unavoidable and often neglected environmental issue. At present, however, water monitoring standards do not include pharmaceutical and personal care products (PPCPs), which are recalcitrant to biodegradation or complete removal via traditional sewage treatment processing technologies (Christina et al., 2014). Concurrently, PPCPs are constantly released into the environment from the medical and livestock industries; hence, they have garnered the attention of researchers and the public due to their "pseudo persistence." Common PPCPs include non-steroidal anti-inflammatory and analgesic drugs such as Ibuprofen, Naproxen, Aspirin, and Diclofenac. Naproxen (NPX) is a commonly used anti-inflammatory and analgesic with negligible side effects; thus, it is one of the four most commonly consumed prescriptions on a global scale (Jones et al., 2002). Although the NPX concentration in water is low, it has accumulated to $\mathrm{ng} / \mathrm{L}$ concentration levels (Dai et al., 2014). Medical studies have revealed that the long-term ingestion of trace NPX levels can induce heart disease, stroke, and toxic pulmonary effects (Isidori et al., 2005; Karl et al., 2006; Domínguez et al., 2011; Hasan et al., 2012). Current NPX treatment methods encompass adsorption (Xu et al., 2009; Hasan et al., 2012) photocatalytic degradation 
(Méndez-Arriaga et al., 2008), and radiation (Zheng et al., 2011), which commonly employ $\mathrm{FeOOH}$ (the primary component of rust, a corrosion product on metal surfaces) (Molgaard, 1974). It has been reported that $\mathrm{FeOOH}$ exists not only in marine shellfish (Lee et al., 2000), but also within soils, sediments, and water, and the physical and chemical properties of $\mathrm{FeOOH}$ are stable. This compound possesses a relatively large surface area, which likely plays a critical role in the removal of contaminants from the natural environment (Fortin and Langley, 2005; Zhou et al., 2007); hence, it is receiving increased attention in the areas of environmental restoration and governance.

Nano- $\gamma$ - $\mathrm{FeOOH}$ exhibits surface resident and interfacial effects as well as unique properties at the nanoscale and quantum levels (Nurmi et al., 2005). It can effectively adsorb organic matter in water and demonstrates a good flocculation effect. Under certain conditions of light and oxygen exposure, it may also catalyze the degradation of adsorbed organic matter without producing secondary pollution. At present, $\gamma$ $\mathrm{FeOOH}$ is mainly used for industrial desulfurization; thus, there have been few studies on the adsorption and photocatalysis of PPCP contaminants. Further, investigations of NPX-related adsorption and photocatalytic processes and mechanisms have rarely been reported.

For this investigation, nano- $\gamma-\mathrm{FeOOH}$ is synthesized, and on the basis of previous studies that examined its adsorption performance for NPX (Zhanyi et al., 2018), the primary focus here is centered on the effects of nano- $\gamma-\mathrm{FeOOH}$ on the photocatalytic degradation of NPX. The effects of the photocatalyst dosage, initial NPX concentration, $\mathrm{pH}$, and other factors are investigated. This work culminates in the proposal of an environmentally compatible photocatalytic strategy for the effective treatment of NPX-infused wastewater.

\section{EXPERIMENT}

\section{Materials and Reagents}

NPX (A-methyl-6-methoxy-2-naphthaleneacetic acid, 98\% purity) was obtained from West Asia Reagent Company. Acetonitrile (CR), methanol (CR), and ethanol (CR) were obtained from USA ACS Enke Chemical. $\mathrm{FeSO}_{4} \cdot 7 \mathrm{H}_{2} \mathrm{O}$ (AR), $\mathrm{NH}_{3} \cdot \mathrm{H}_{2} \mathrm{O}$ (AR), EDTA (AR), $\mathrm{NaOH}(\mathrm{AR}), \mathrm{H}_{2} \mathrm{SO}_{4}$ (AR), KI (AR), IPA (Isopropanol, AR), $\mathrm{NaN}_{3}$ (AR), and p-BQ (pBenzoquinone, AR) were obtained from Shanghai Aladdin Bio-Chem Technology Co., Ltd. Ultrapure water employed in the experiments was obtained via an integrated Smart2 Pure ultrapure water system, obtained from TKA Wasseraufbereitungs system GmbH, Germany.

\section{Synthesis of Nanostructured $\gamma$-FeOOH}

Freshly prepared under magnetic stirring, $10 \mathrm{ml}$ of pure $\mathrm{NH}_{3} \cdot \mathrm{H}_{2} \mathrm{O}$ was added to a $110 \mathrm{ml} 0.3 \mathrm{~mol} \cdot \mathrm{L}^{-1} \mathrm{FeSO}_{4}$ solution, which had a $\mathrm{pH}$ of 8.6 . Subsequently, $10 \mathrm{ml}$ of $0.015 \mathrm{~mol} \cdot \mathrm{L}^{-1}$ EDTA and ultrapure water were added to a $150-\mathrm{ml}$ volume. Then, $1 \mathrm{~L} \cdot \mathrm{min}^{-1} \mathrm{O}_{2}$ was introduced into the solution for about 30 min until the precipitation color changed from blue-green to orange under a controlled system temperature of $20^{\circ} \mathrm{C}$, after which the $\mathrm{pH}$ was maintained at 4.3 . Once the orange precipitate was filtered and rinsed, it was placed in a vacuum drying oven for $24 \mathrm{~h}$ at $30^{\circ} \mathrm{C}$. Thereafter, the sample was finely ground and screened (200 mesh) (He et al., 2005).

\section{Characterization of Nanostructured $\gamma$-FeOOH}

$\mathrm{X}$-ray diffraction (XRD) was carried out with a $\mathrm{Cu} \mathrm{K}(\alpha)$ source $(\lambda=0.15406 \mathrm{~nm})$ at $40 \mathrm{kV}$ and $30 \mathrm{~mA}$ over the range of $2 \theta=20-80^{\circ}$.

Scanning electron microscopy (SEM) was used for investigating the morphology and dispersion of the samples. Prior to measurements, the sample was affixed to an aluminum sheet and sprayed with gold.

BET surface area (BET) analysis was used to determine the pore structure, specific surface area, and porosity of the samples. The porosity and pore distribution were determined by a nitrogen adsorption-desorption isotherm and the BarrettJoyner-Halenda (BJH) method.

\section{Photocatalytic NPX Degradation Experiments \\ Photoreaction Apparatus and Procedure}

The photocatalytic NPX degradation experiments using $\gamma$ $\mathrm{FeOOH}$ were carried out using a multifunctional photochemical reaction instrument with magnetic stirring bars and a cooling circulation system (Figure 1). The illumination source in the experiment was a $300-\mathrm{W}$ mercury lamp (Table 1), which was $10 \mathrm{~cm}$ away from the quartz tubes, and the temperature was held steady at $25^{\circ} \mathrm{C}$ during all tests. Prior to the photocatalytic degradation tests, the $\gamma$-FeOOH/NPX system was allowed to reach adsorption-desorption equilibrium in the dark for $240 \mathrm{~min}$ (He et al., 2005; Zhanyi et al., 2018). Subsequently, each experiment was conducted in triplicate with 20 - $\mathrm{ml}$ samples under UV irradiation, and the rotary reactor was rotated at $5 \mathrm{rpm}$ for $1 \mathrm{~min}$, accompanied by constant magnetic stirring at 100 rpm for $1 \mathrm{~min}$. A $10-\mathrm{ml}$ sample was extracted via syringe every 2 min for each test and immediately passed through a 0.45 $\mu \mathrm{m}$ filter. The filtrate was then analyzed by high-performance liquid chromatography.

\section{Photodegradation of NPX by $\gamma$-FeOOH}

To determine the effect of $\gamma$-FeOOH dosage, $0.05,0.1,0.2,0.4$, and $0.6 \mathrm{~g} \cdot \mathrm{L}^{-1}$ of $\gamma-\mathrm{FeOOH}$ was added to the NPX solution at a concentration of $10 \mathrm{mg} \cdot \mathrm{L}^{-1}$.

To determine the effect of initial NPX concentration, NPX solutions with several concentrations of $5,10,20,30$, and $40 \mathrm{mg} \cdot \mathrm{L}^{-1}$ were prepared, to which $0.2 \mathrm{~g} \cdot \mathrm{L}^{-1}$ of $\gamma-\mathrm{FeOOH}$ was added.

To determine the effect of $\mathrm{pH}$, the $\mathrm{pH}$ was adjusted to 5,7 , and 9 by adding $0.1 \mathrm{~mol} \cdot \mathrm{L}^{-1} \mathrm{H}_{2} \mathrm{SO}_{4}$ or $0.1 \mathrm{~mol} \cdot \mathrm{L}^{-1} \mathrm{NaOH}$ to the NPX solution with a concentration of $10 \mathrm{mg} \cdot \mathrm{L}^{-1}$, to which exactly 0.2 $\mathrm{g} \cdot \mathrm{L}^{-1}$ of $\gamma-\mathrm{FeOOH}$ was added.

The above experiments proceeded as described above.

\section{Langmuir-Hinshelwood Kinetics}

Heterogeneous photocatalysis includes two basic reaction steps, which are physical adsorption and a chemical reaction. For our 


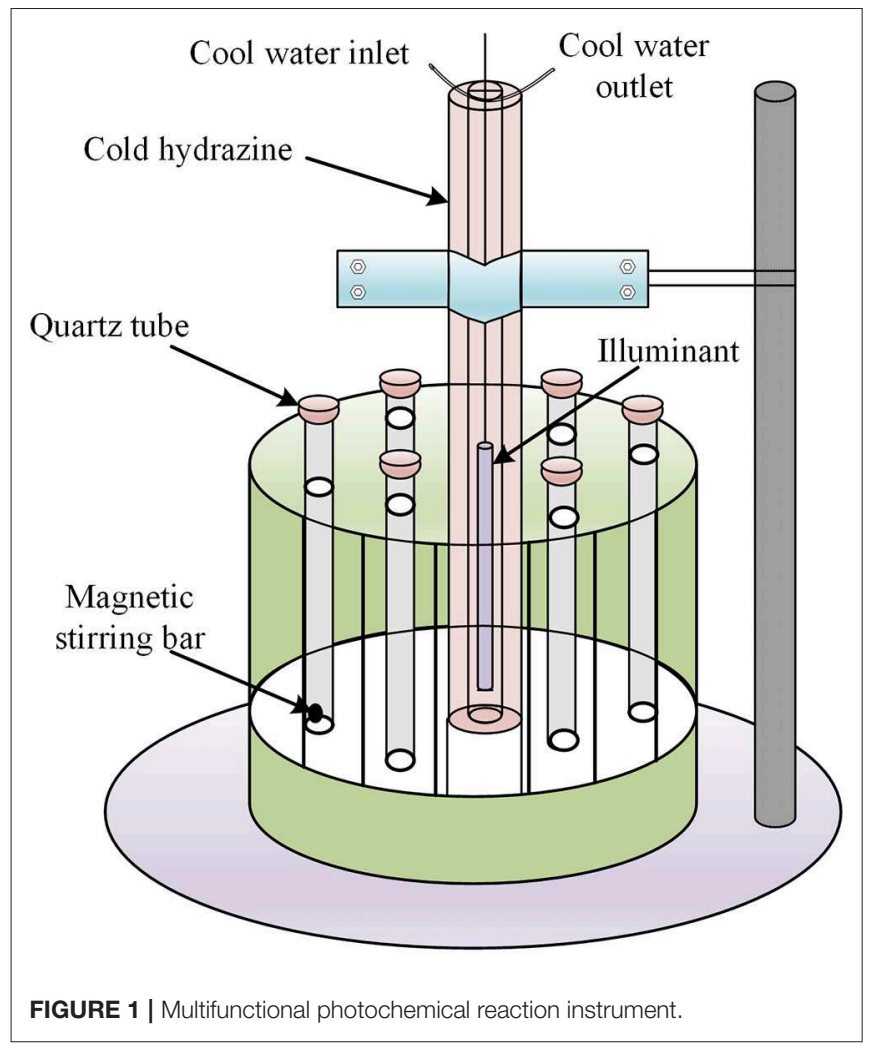

TABLE 1 | Mercury lamp energy distribution.

\begin{tabular}{lccc}
\hline $\begin{array}{l}\text { Wavelength } \\
\boldsymbol{\lambda} \text { (nm) }\end{array}$ & $\begin{array}{c}\text { Relative energy } \\
\mathbf{( \% )}\end{array}$ & $\begin{array}{c}\text { Wavelength } \\
\boldsymbol{\lambda} \text { (nm) }\end{array}$ & $\begin{array}{c}\text { Relative energy } \\
\mathbf{( \% )}\end{array}$ \\
\hline 1,367 & 15.3 & 289 & 6.0 \\
1,129 & 12.6 & 280 & 9.3 \\
1,014 & 40.6 & 275 & 2.7 \\
$577-579$ & 76.5 & 270 & 4.0 \\
546 & 93.0 & 265 & 15.3 \\
436 & 77.5 & 257 & 6.0 \\
$405-408$ & 42.2 & 254 & 16.6 \\
$365-366$ & 100.0 & 248 & 8.6 \\
334 & 9.3 & 240 & 7.3 \\
313 & 49.9 & 238 & 8.6 \\
$302-303$ & 23.9 & 236 & 6.0 \\
297 & 16.6 & 232 & 8.0 \\
\hline
\end{tabular}

experiments, Langmuir-Hinshelwood kinetics (L-H equation) were employed to fit the relationship between the photocatalytic reaction rate $(r)$ and solution concentration $(C)$ :

$$
r=\frac{d C}{d t}=k_{\mathrm{L}-\mathrm{H}} \frac{K C}{1+K C}
$$

where $r$ is the initial photodegradation rate of NPX measured in $\mathrm{mg} \cdot \mathrm{L}^{-1} \cdot \mathrm{min}^{-1}, k_{\mathrm{L}-\mathrm{H}}$ is the photocatalytic degradation rate constant measured in $\mathrm{mg} \cdot \mathrm{L}^{-1} \cdot \mathrm{min}^{-1}, K$ is the adsorption constant of NPX on the surface of $\gamma$-FeOOH measured in $\mathrm{L} \cdot \mathrm{mg}^{-1}$, and $C$ is the instantaneous concentration of NPX measured in $\mathrm{mg} \cdot \mathrm{L}^{-1}$.
There was a linear relationship between the reciprocal of $r$ $(1 / r)$ and the reciprocal of $C(1 / C)$. Linear fitting was applied with the data from the experiment; hence, the photocatalytic degradation rate constant $k_{\mathrm{L}-\mathrm{H}}$ and the adsorption constant $K$ were obtained and found to be independent of the NPX concentration.

$$
\frac{1}{r}=\frac{1}{k_{L-H}}+\frac{1}{k_{L-H} K} \cdot \frac{1}{C}
$$

\section{Active Species Analysis}

In order to investigate the role of free radicals in the photocatalytic degradation of NPX, radical quenching experiments were carried out. Four solutions were prepared, comprising $10 \mathrm{mg} \cdot \mathrm{L}^{-1} \mathrm{NPX}$ and $0.2 \mathrm{~g} \cdot \mathrm{L}^{-1} \gamma$-FeOOH, to which $50 \mathrm{mmol} \cdot \mathrm{L}^{-1}$ potassium iodide $(\mathrm{KI}), 0.10 \mathrm{mmol} \cdot \mathrm{L}^{-1}$ isopropanol (IPA), $0.01 \mathrm{mmol} \cdot \mathrm{L}^{-1}$ sodium azide $\left(\mathrm{NaN}_{3}\right)$, and $0.01 \mathrm{mmol} \cdot \mathrm{L}^{-1}$ benzoquinone (BQ) were added. In particular, KI was employed to quench the $\mathrm{h}^{+}$and $\cdot \mathrm{OH}$ radicals (Zhang et al., 2011).

\section{RESULTS AND DISCUSSION}

\section{Characterization of $\gamma$-FeOOH}

The physical properties of metal oxides, such as their crystal structures and surface characteristics, may influence their photocatalytic activity. Eight peaks were observed in the XRD pattern of $\mathrm{FeOOH}$ that were attributed to the (120), (011), (031), (111), (060), (220), (151), and (080) planes, indicating the presence of the $\gamma$ structure (Figure 2A). When compared with the standard diffraction peaks of $\gamma-\mathrm{FeOOH}$, the prepared powder was in the form of a pure crystal phase.

Surface morphological studies of $\gamma$-FeOOH by SEM revealed that the prepared powder was in the form of a mixed crystal phase, which contained, for the most part, nanoparticles ( $\sim 50 \mathrm{~nm}$ ) and short nanorods ( $\sim 200 \mathrm{~nm}$ in length) (Figure $2 B$ ), due to differences in $\mathrm{pH}$ during the preparation of $\gamma-\mathrm{FeOOH}$ (Farcasiu et al., 1991). The smooth and dispersible properties of the mixed crystal phase revealed that the morphology was relatively regular.

The adsorption capacity of metal oxides for organic pollutants is affected by the BET size. On the basis of the $\mathrm{N}_{2}$ adsorptiondesorption isotherm and pore size distribution, the specific surface area of $\gamma$-FeOOH was determined to be $125.7 \mathrm{~m}^{2} \cdot \mathrm{g}^{-1}$ (Figure 2C). As shown in Figure 2C, we found that there was a significant hysteresis loop in the adsorption-desorption curve, which means that the sample possessed a mesoporous structure. According to the $\mathrm{BJH}$ desorption curve method (Kruk et al., 1997), which was employed to calculate the pore size distribution, the pore size range of the sample was $\sim 50 \mathrm{~nm}$. In photocatalytic experiments, $\gamma$-FeOOH was recovered and washed with pure water three times before drying. The XRD pattern showed no obvious change (Figure 2D) after this test. The degradation of NPX was reduced by only $1 \%$ when performing photodegradation with the recovered $\gamma$ $\mathrm{FeOOH}$. These results show that the $\gamma$-FeOOH photocatalyst is highly stable.

As shown in Figure 3A, $\gamma$-FeOOH displayed a typical absorption edge at $\sim 650 \mathrm{~nm}$, and a bandgap width of $1.94 \mathrm{eV}$ 
A

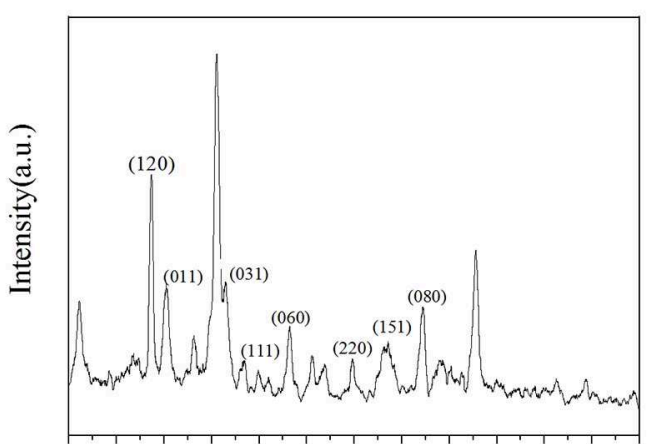

$\begin{array}{llllllllllllllll}20 & 25 & 30 & 35 & 40 & 45 & 50 & 55 & 60 & 65 & 70 & 75 & 80\end{array}$

$2 \theta /\left({ }^{\circ}\right)$

C

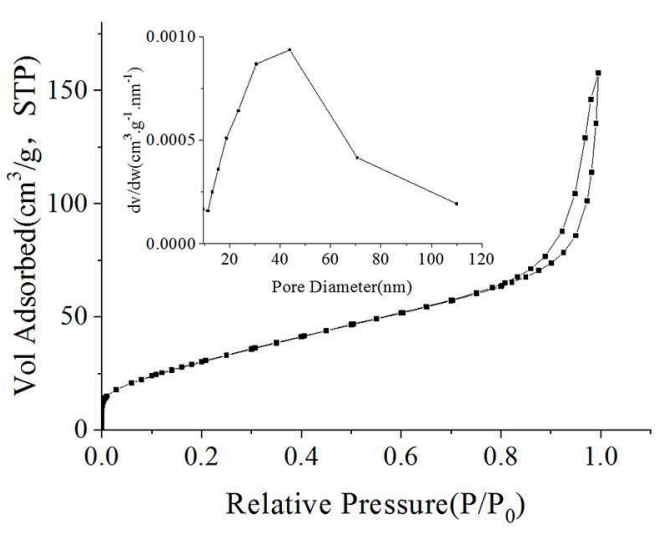

B

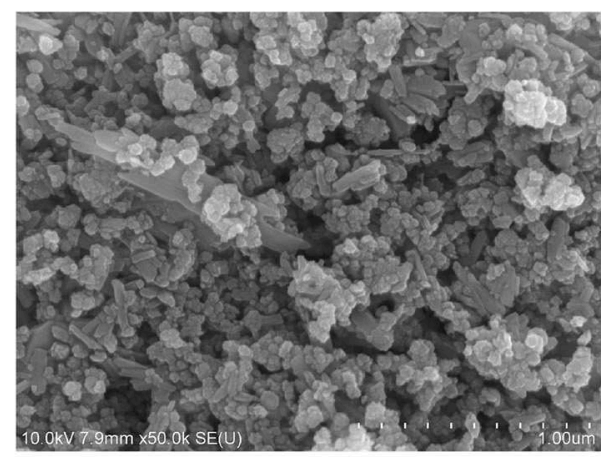

D

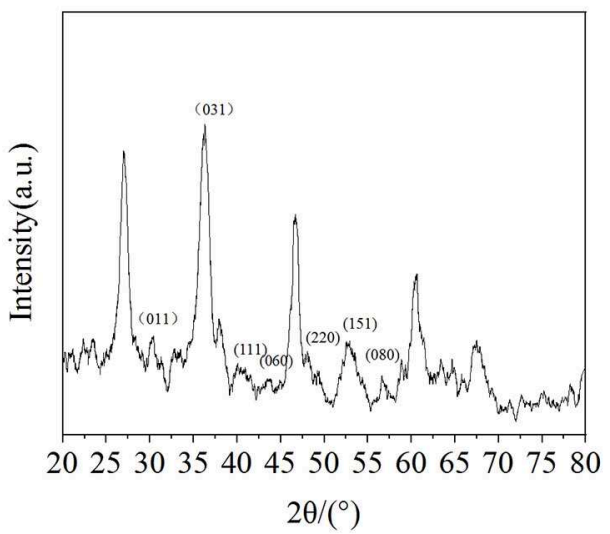

FIGURE 2 | (A) XRD pattern of $\gamma$-FeOOH, (B) SEM image of $\gamma$-FeOOH, (C) $\mathrm{N}_{2}$ adsorption-desorption isotherm and pore size distribution of $\gamma$-FeOOH, (D) XRD pattern of recycled $\gamma$-FeOOH.

was calculated (Figure 3B). In order to further study the bandgap position of the semiconductor $\gamma$-FeOOH, X-ray photoelectron spectroscopy (XPS) was used to probe the valence band (XPS$\mathrm{VB})$. This revealed that the valence band of $\gamma$-FeOOH was located at $1.80 \mathrm{eV}$, as shown in Figure 3C. Therefore, it can be deduced that the rewind position of $\gamma-\mathrm{FeOOH}$ was $-0.14 \mathrm{eV}$ and the band gap structure is shown in Figure 3D.

\section{Effect of $\gamma$-FeOOH Dosage on the Photocatalytic Degradation of NPX}

A suspension was formed in the multiphase photocatalytic reaction system, as the catalyst is insoluble in water. With increased catalyst dosages, the effective surface area of the solution was increased; hence, its reaction efficacy was enhanced proportionally. Excessive catalyst loading caused reflection and scattering, which reduced the transmittance of the solution and thus the catalytic efficiency. It was observed that the $\gamma$-FeOOH dosage played a very important role in the photodegradation of NPX. To investigate the effect of $\gamma$-FeOOH dosage on the photodegradation of NPX, $\gamma$-FeOOH solutions were prepared at concentrations of $0.05,0.1,0.2,0.4$, and $0.6 \mathrm{~g} \cdot \mathrm{L}^{-1}$, which were then introduced into separate NPX solutions. As shown in
Figure 4A, the data collected from the photodegradation of NPX following the addition of different concentrations of $\gamma-\mathrm{FeOOH}$ were fitted to a first-order kinetic equation. It was observed that the NPX photodegradation rate increased with increased $\gamma$-FeOOH loading in water.

When the dosage of $\gamma$-FeOOH was varied from 0.05 to $0.6 \mathrm{~g} \cdot \mathrm{L}^{-1}$, the NPX photodegradation rate increased from 0.0344 to $0.0509 \mathrm{~min}^{-1}$. The position and photogenic charge of photocatalytic reactions in the system were enhanced with increased $\gamma$-FeOOH loading; however, the shielding, reflection, and scattering of light were increased with higher $\gamma$-FeOOH loads. With appropriate loads of $\gamma-\mathrm{FeOOH}$, the transmittance of light in the solution decreased and the reaction rate slowly increased.

During the process of photodegradation, the relationship between the reaction rate constant $k$ and the concentration of $\gamma$ $\mathrm{FeOOH}$ was fitted to the following empirical formula (Galindo et al., 2001):

$$
\begin{array}{r}
k=a[\gamma-\mathrm{FeOOH}]^{n} \\
\ln k=\ln a+n \ln [\gamma-\mathrm{FeOOH}]
\end{array}
$$



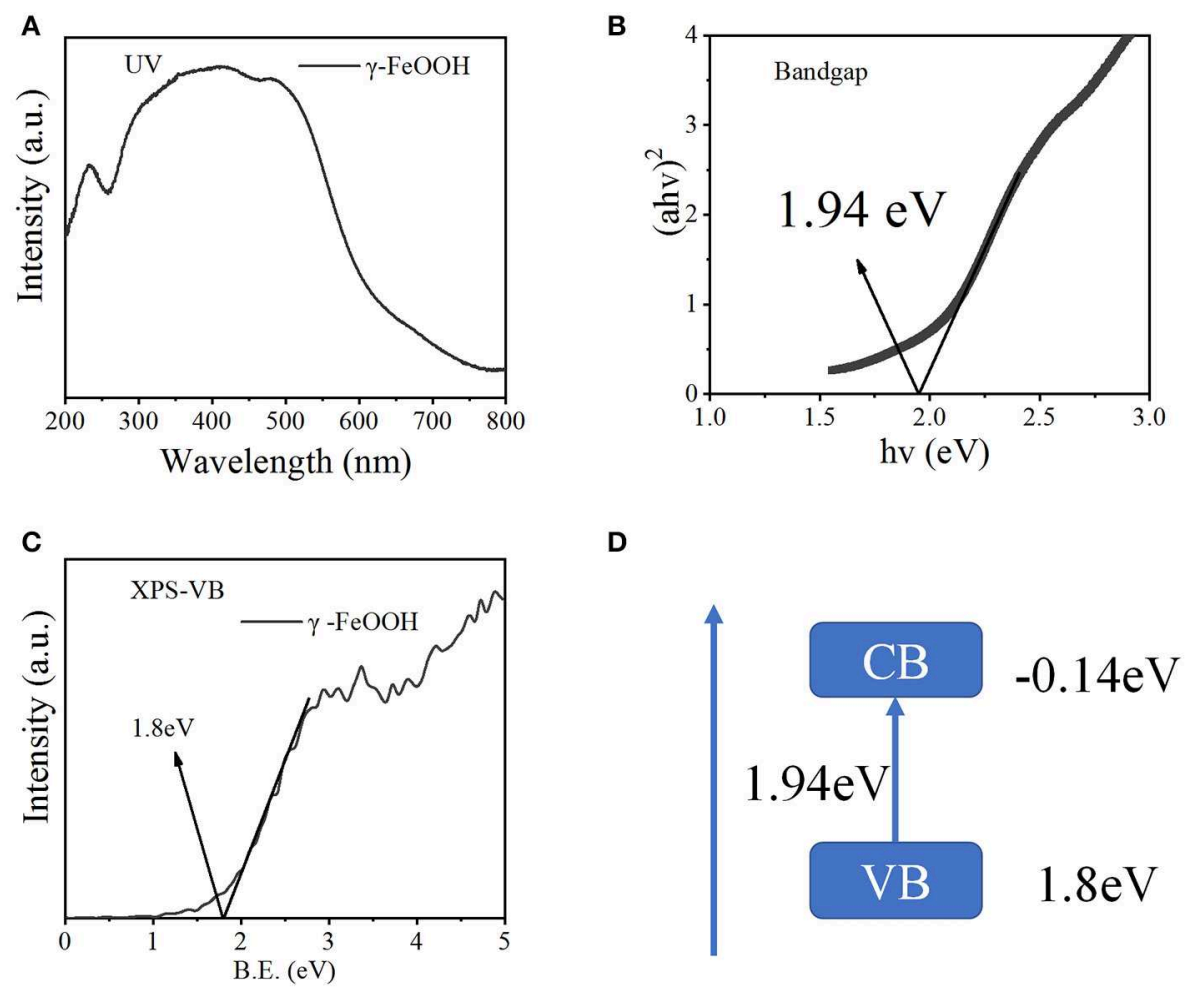

FIGURE 3 | (A) UV-Vis diffuse spectra of $\gamma$-FeOOH, (B) bandgap width of $\gamma$-FeOOH, (C) XPS-VB spectra of $\gamma$-FeOOH, and (D) band structure alignments of $\gamma$-FeOOH.
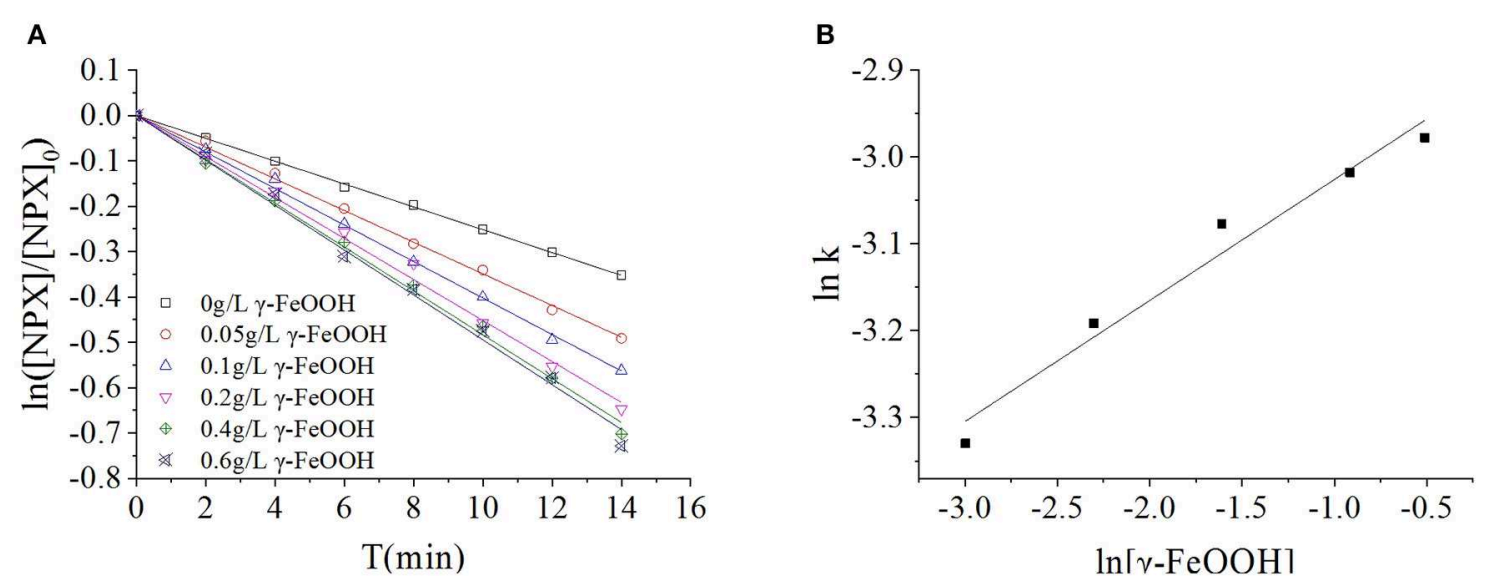

FIGURE 4 | (A) Influence of $\gamma$-FeOOH dosage on NPX photodegradation, and (B) influence of $\gamma$-FeOOH dosage on the NPX photodegradation rate constant.

where $n$ is the correlation index and $[\gamma-\mathrm{FeOOH}]$ is the concentration of $\gamma$ - $\mathrm{FeOOH}\left(\mathrm{g} \cdot \mathrm{L}^{-1}\right)$.

The kinetic constants of NPX photodegradation and the dosage of $\gamma$ - $\mathrm{FeOOH}\left(0.05\right.$ to $\left.0.6 \mathrm{~g} \cdot \mathrm{L}^{-1}\right)$ in this experiment were analyzed by linear regression, with the relationship between $k$ and $[\gamma-\mathrm{FeOOH}]$ shown in Figure 4B:

$$
\ln k=\ln 0.05577+0.1394 \ln [\gamma-\mathrm{FeOOH}] \quad\left(R^{2}=0.9832\right)
$$

To: $k=0.05577[\gamma-\mathrm{FeOOH}]^{0.1394}$

\section{Effect of Initial NPX Concentration on the $\gamma$-FeOOH/NPX System}

It has been suggested that the charge transfer process between the contaminants adsorbed to the catalyst surface and the lightgenerated active species $\left(\mathrm{h}^{+}, \mathrm{OH}\right.$, and $\mathrm{O}_{2} \cdot$ ) facilitates the photocatalytic oxidation of pollutants in solution. Therefore, the 
coverage of pollutants on the catalyst surface has an important influence on photocatalytic activity.

In this section, the photodegradation of NPX by $0.2 \mathrm{~g} \cdot \mathrm{L}^{-1}$ $\gamma$-FeOOH was investigated at initial NPX concentrations of 5 , 10, 20, 30, and $40 \mathrm{mg} \cdot \mathrm{L}^{-1}$, with the results shown in Figure 5A. These experiments revealed that the photodegradation of NPX followed first-order kinetics at different initial concentrations upon the addition of $\gamma$-FeOOH. The activities of semiconductor photocatalysts arise primarily from photogenic $\mathrm{e}^{-}$and $\mathrm{h}^{+}$, where, in the competitive process of photocatalysis, they may be recombined very rapidly (generally at the nanosecond level) (Hoffmann et al., 1995). From the kinetics perspective, only the adsorbents on the surface of the catalyst may be oxidized by $\mathrm{e}^{-}$. However, our results revealed that the NPX photodegradation rate decreased with higher initial concentrations in solution.

Under a certain light intensity, higher initial NPX concentrations resulted in a lower population of photons available per NPX molecule; hence, a lower photodegradation rate was obtained. An identical result was reported in previous NPX research (Ma et al., 2013). Secondly, higher initial NPX concentrations, with additional particles adsorbed to the $\gamma$ FeOOH surface, acted to lower the number of photocatalytically active sites that were available at the surface. Hence, the population of photogenerated $\mathrm{e}^{-} / \mathrm{h}^{+}$pairs per unit of time was correspondingly reduced. Simultaneously, prior to the photodegradation of NPX molecules, they were required to undergo charge exchange with the active species generated at the $\gamma$-FeOOH surface and diffuse into the solution. Finally, when the initial NPX concentration was increased, it was difficult to completely decompose the reaction-generated intermediate products in a timely manner. This increased the opposition against adsorption to the surface of the $\gamma-\mathrm{FeOOH}$, where these intermediates could once again reform the NPX matrix. Therefore, the photodegradation rate was finally decreased.

We considered the derivative of the obtained first-order kinetic equation with respect to $t$ and set $t=0$ to obtain the photodegradation rate $r_{0}$ under different initial concentrations of $C_{0}$, as shown in Figure 5B. When the initial concentration of NPX was increased from 5 to $40 \mathrm{mg} \cdot \mathrm{L}^{-1}$, the initial photodegradation rate $r_{0}$ also increased gradually, from 0.1415 to $0.7997 \mathrm{mg} \cdot \mathrm{L}^{-1} \cdot \mathrm{min}^{-1}$. This indicated that the photocatalytic degradation of NPX occurred on the surface of $\gamma$-FeOOH, and the photodegradation rate was an increasing function of the level of surface adsorption. When the Metastable-Equilibrium Adsorption Theory (Pan and Liss, 1998) is regarded under certain thermodynamic conditions, the adsorption amount is related to the surface binding strength and the adsorption configuration, while being balanced with the concentration of the solute. In this section, when the initial NPX concentration was raised, the coverage rate of the NPX molecules on the surface of $\gamma$-FeOOH increased accordingly. Consequently, the electron transfer efficiency of the NPX molecules that was adsorbed to the surface and the photogenerated charge were increased, which led to an increase of the initial photodegradation rate $r_{0}$.

A large quantity of experimental data has indicated that the photocatalytic degradation of organic pollutants on the surface of semiconductors conforms to the Langmuir-Hinshelwood kinetic equation (Hoffmann et al., 1995; Houas et al., 2001; Andreozzi et al., 2003; Du et al., 2008; Li et al., 2008). The applicable premise of the $\mathrm{L}-\mathrm{H}$ kinetic equation is that the organic pollutant molecules are adsorbed to a solid surface (Turchi and Ollis, 1990; Alfano et al., 1997). Although researchers have not clarified the photocatalytic mechanisms of $\mathrm{FeOOH}$, surface complexes (Faust and Hoffmann, 1986) and semiconductorinitiated photocatalytic mechanisms (Bandana et al., 1999) have had their respective supporters. More recent studies have supported semiconductor photocatalytic mechanisms and highlighted the role of organic pollutant molecules adsorbed to the FeOOH surface (Bandana et al., 1999, 2001a,b). In examining the $\mathrm{FeOOH}$-facilitated photocatalysis of orange II, $\mathrm{Du}$ et al. (2008) analyzed the initial reaction rate, amount of $\mathrm{FeOOH}$ surface adsorption, and the position of the $\mathrm{FeOOH}$ activity. Thus, Du considered that the $\mathrm{FeOOH}$ photocatalytic reaction takes place at the solid surface; therefore, the available $\mathrm{L}-\mathrm{H}$ kinetic equation could be employed to describe $\mathrm{FeOOH}$ photocatalysis. Based on this, $1 / C_{0}$ and $1 / r_{0}$ were calculated according to Equation (2), and a plot was created for $1 / C_{0^{-}}$ $1 / r_{0}$ (as shown in Figure 5C). A linear relationship was found between them within the experimental concentration range $\left(R^{2}\right.$ $=0.9996), k_{\mathrm{L}-\mathrm{H}}=2.1867 \mathrm{mg} \cdot \mathrm{L}^{-1} \cdot \mathrm{min}^{-1}, \mathrm{~K}=0.01377 \mathrm{~L} \cdot \mathrm{mg}^{-1}$. This signified that the photocatalytic degradation of NPX on the surface of $\gamma$-FeOOH satisfies the $\mathrm{L}-\mathrm{H}$ kinetic equation, and that the adsorption of NPX on $\gamma-\mathrm{FeOOH}$ is of importance to its photocatalytic degradation ( $\mathrm{Li}$ et al., 2008).

Within the range of experimental concentrations, the photodegradation kinetic constant of NPX gradually decreased (from 0.0285 to $0.0200 \mathrm{~min}^{-1}$ ), whereas the correlation coefficient $R^{2}$ decreased from 0.9949 to 0.9791 . The relationship between the reaction rate constant $k$ and the initial substrate concentration during the photocatalytic process could be generally described by the following empirical formula:

$$
\begin{array}{r}
k=a[N P X]^{n} \\
\ln k=\ln a+n \ln [N P X]
\end{array}
$$

where $n$ is the correlation index and [NPX] is the initial concentration of NPX $\left(\mathrm{mg} \cdot \mathrm{L}^{-1}\right)$.

Linear regression was used to analyze the relationship between the NPX photodegradation kinetic constant and its initial concentration (5-40 $\mathrm{mg} \cdot \mathrm{L}^{-1}$ ) within the experimental range. It can be seen in Figure 5D that the relationship between the reaction rate constant $k$ and NPX concentration was as follows:

$$
\begin{array}{r}
\ln k=\ln 0.03790-0.1673 \ln [N P X] \quad\left(R^{2}=0.9848\right) \\
k=0.03790[N P X]^{-0.1673}
\end{array}
$$

\section{Effect of $\mathrm{pH}$ on the $\gamma$-FeOOH/NPX System}

It is understood that $\mathrm{pH}$ is a critical factor that influences the photocatalytic degradation kinetics during semiconductor multiphase photocatalysis. First, $\mathrm{pH}$ can change the charge properties of the catalyst surface and affect how organic molecules adsorb on the catalyst surface (Barnard et al., 2005). Secondly, photogenerated charge carriers can combine with $\mathrm{H}^{+} / \mathrm{OH}^{-}$in solution to form active species, such as $\mathrm{OH}^{-}$, which 
A

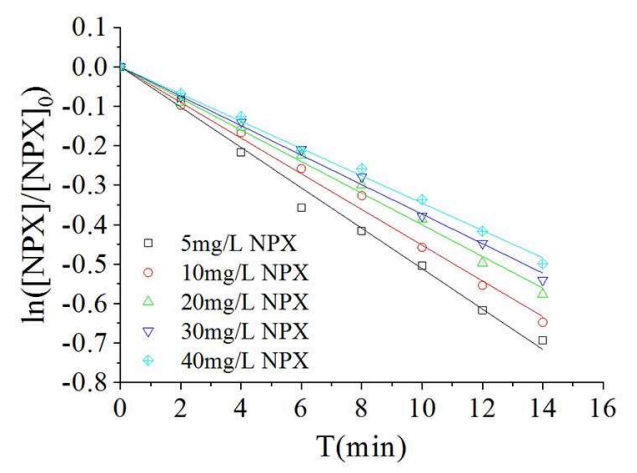

C

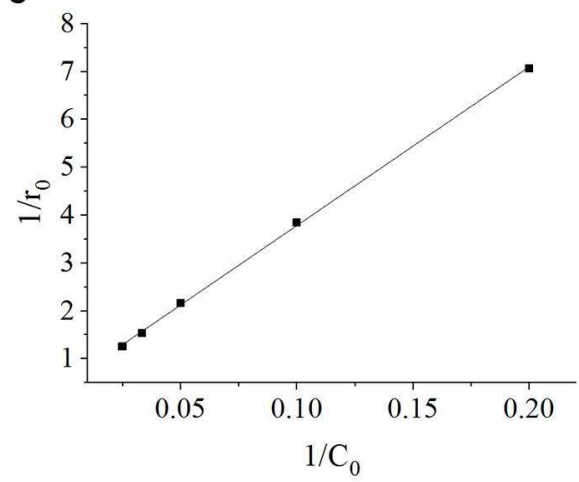

B

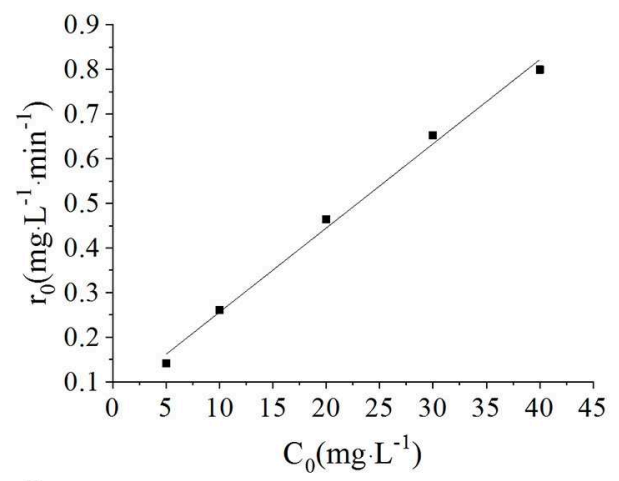

D

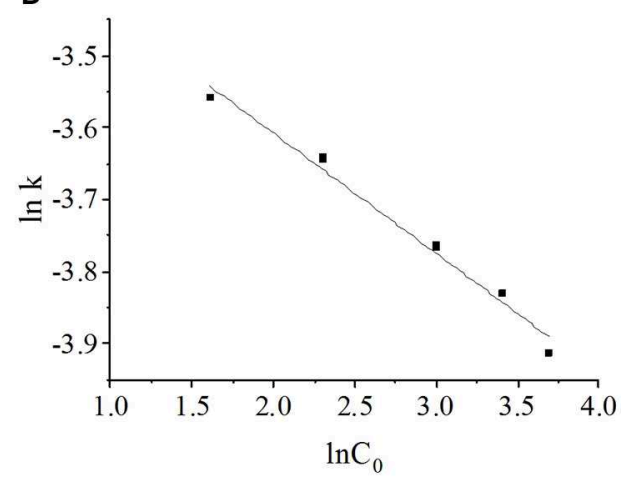

FIGURE 5 | (A) Influence of initial NPX concentrations on the photodegradation of $\gamma$-FeOOH/NPX; (B) the initial reaction rate $r_{0}$ as a function of initial NPX concentration $\mathrm{C}_{0}$; (C) Langmuir-Hinshelwood model of photocatalytic NPX degradation by $\gamma$-FeOOH; (D) influence of initial NPX concentrations on the photodegradation rate constant of $\gamma-\mathrm{FeOOH} / \mathrm{NPX}$.

can capture photogenerated holes $\mathrm{H}^{+}$to form $\cdot \mathrm{OH}$. Finally, $\mathrm{pH}$ may alter the electron cloud density distribution of organic molecules, thus affecting photocatalytic degradation.

As the effects of $\mathrm{pH}$ on photocatalytic degradation kinetics are relatively complex, definitive studies of $\gamma-\mathrm{FeOOH}$ are relatively rare. In this section, to investigate the effects of initial $\mathrm{pH}$ on the photodegradation of $\gamma$ - $\mathrm{FeOOH} / \mathrm{NPX}$ reaction systems, the initial NPX concentration was established as $10 \mathrm{mg} \cdot \mathrm{L}^{-1}$, whereas that of $\gamma$ - $\mathrm{FeOOH}$ was $0.2 \mathrm{~g} \cdot \mathrm{L}^{-1}$, and the initial $\mathrm{pH}$ of the photodegradation solution was set at 5,7 , and 9. As shown in Figure 6A, at a pH of 5, the $\gamma$-FeOOH /NPX system demonstrated the fastest photocatalytic rate with a $\mathrm{pH}$ of 9 in the second place, while the slowest rate was observed at a $\mathrm{pH}$ of 7 , much the same as the photocatalytic rates observed in water (Figure 6B).

As $\mathrm{pH}_{\mathrm{ZPC}}=8.47$ for $\gamma-\mathrm{FeOOH}$, the hydroxylation of the $\gamma$ FeOOH surface in an alkaline solution could allow $\mathrm{OH}^{-}$to react with $\mathrm{h}^{+}$to produce $\cdot \mathrm{OH}$ as follows:

$$
\mathrm{Fe}^{\mathrm{III}}-\mathrm{OH}^{-}+\mathrm{h}^{+} \rightarrow \mathrm{Fe}^{\mathrm{III}}+\cdot \mathrm{OH}
$$

Concurrently, the ether bonds of the NPX molecules are less stable under acidic conditions (Chen et al., 2013). Hence, $\gamma$ $\mathrm{FeOOH}$ was favorable for the photocatalytic degradation of NPX at $\mathrm{pH}<7$.
Based on the above analysis, when the $\mathrm{pH}$ was low, the stability of the ether bonds within the NPX molecules was decreased, which enabled the $\gamma$-FeOOH-based photocatalytic degradation of NPX. When the $\mathrm{pH}$ was high, $\mathrm{OH}^{-}$combined with $\mathrm{h}^{+}$ to form $\cdot \mathrm{OH}$, which facilitated the photocatalytic degradation of NPX. Due to the combined effect of these two factors, the reaction rate was lowest when the $\mathrm{pH}$ was 7 within the range of our experiments.

\section{Analysis of the Photocatalytic Degradation Mechanism of $\gamma$-FeOOH}

Quenching experiments were carried out (Figure 7A) by measuring the generation of active species during the photodegradation of NPX in pure water. It can be seen that there was not only direct photodegradation caused by ${ }^{3} \mathrm{NPX}^{*}$, but also self-sensitized photodegradation involving hydroxyl radicals $(\cdot \mathrm{OH})$, singlet oxygen $\left({ }^{1} \mathrm{O}_{2}\right)$, and superoxide anions $\left(\mathrm{O}_{2}^{--}\right)$which were produced in the photodegradation process of NPX (Figure 7B) (Zhanyi et al., 2018).

To further investigate the active radicals that participate in the photodegradation of NPX, electron paramagnetic resonance (EPR) measurements were carried out. As shown in Figure 8A, there was no signal in the dark, while the signal 1:1:1:1 appeared after $5 \mathrm{~min}$ of illumination. It could thus be concluded that 

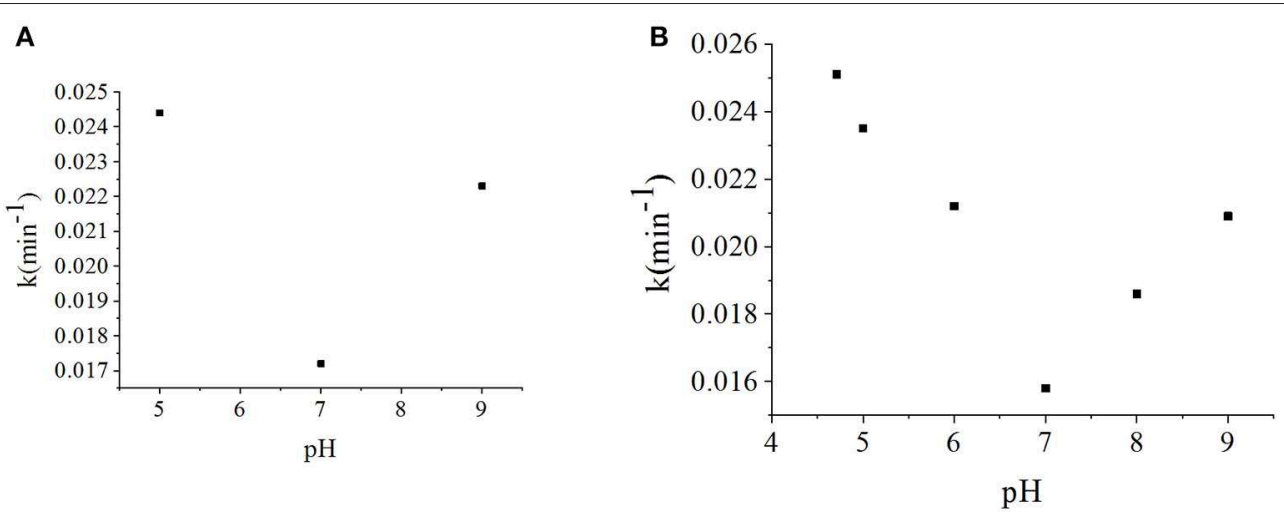

FIGURE 6 | (A) Influence of the $\mathrm{pH}$ value on photodegradation rate constant of $\gamma$ - $\mathrm{FeOOH} / \mathrm{NPX}$, and (B) influence of the $\mathrm{pH}$ value on photodegradation of NPX.

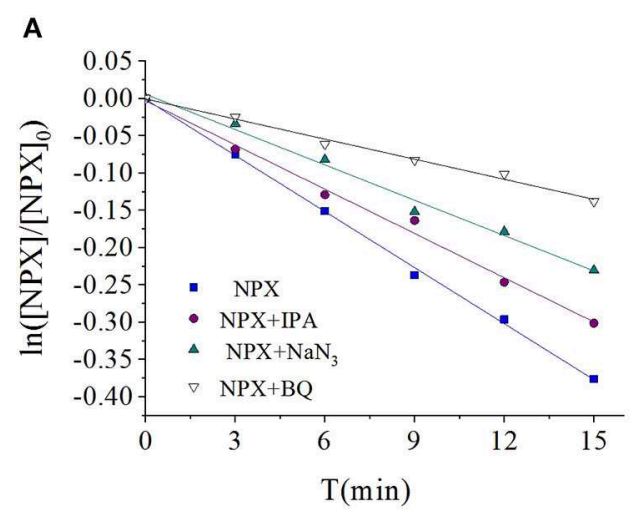

B
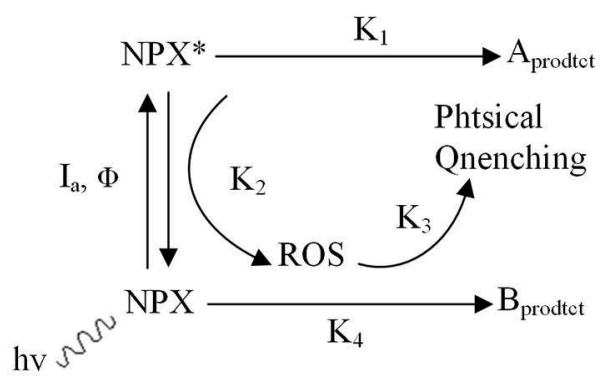

FIGURE 7 | (A) Influence of scavengers on the NPX photodegradation rate constant, and (B) photodegradation of NPX in the water.

$\mathrm{O}_{2}^{--}$was present and its concentration would be increased by illumination. As shown in Figure $\mathbf{8 B}$, it was observed that the signal 1:2:2:1 appeared. This suggests that $\cdot \mathrm{OH}$ appeared and increased in concentration with illumination. It was also confirmed that ${ }^{1} \mathrm{O}_{2}$ was present by TEMP from Figure $8 \mathrm{C}$, while the signal 1:1:1 was detected in the light. So, the active radicals in the $\gamma$-FeOOH/NPX system were evidenced by electron spin resonance (ESR).

Photocatalytic degradation typically generates a variety of active substances, such as $\mathrm{h}^{+}, \mathrm{e}^{-}, \cdot \mathrm{OH},{ }^{1} \mathrm{O}_{2}$, and $\mathrm{O}_{2}^{-}$ (Hao et al., 2016), with the production processes shown in Equations (8)-(14):

$$
\begin{array}{r}
\gamma-\mathrm{FeOOH}+\mathrm{hv} \rightarrow \mathrm{h}^{+}+\mathrm{e}^{-} \\
\mathrm{h}^{+}+\mathrm{H}_{2} \mathrm{O} \rightarrow \cdot \mathrm{OH}+\mathrm{H}^{+} \\
\mathrm{e}^{-}+\mathrm{O}_{2} \rightarrow \mathrm{O}_{2}^{-} \\
\mathrm{O}_{2}^{--}+\mathrm{H}^{+}+\rightarrow \mathrm{HO}_{2} \\
2 \mathrm{HO}_{2} \rightarrow \mathrm{H}_{2} \mathrm{O}_{2}+{ }^{1} \mathrm{O}_{2} \\
\mathrm{H}_{2} \mathrm{O}_{2}+\mathrm{e}^{-} \rightarrow \cdot \mathrm{OH}+\mathrm{OH}^{-}
\end{array}
$$

According to the quenching experiment described in the section "Active Species Analysis," when KI, IPA, $\mathrm{NaN}_{3}$, and BQ were added to the solution, the photocatalytic NPX degradation rate was reduced by different degrees, as shown in Figure 8D. It may be seen from Figure $8 \mathrm{D}$ that free radicals such as $\mathrm{h}^{+}, \mathrm{e}^{-}$, . $\mathrm{OH},{ }^{1} \mathrm{O}_{2}$, and $\mathrm{O}_{2}^{-}$were involved in the $\gamma$-FeOOH-mediated photocatalytic degradation of NPX.

On one hand, $\gamma$-FeOOH is a semiconductor material with an energy band structure, where the energy barrier (Eg) between the valence band (VB) and the conduction band (CB) is only $2.2 \mathrm{eV}$. When the $\gamma$-FeOOH surface was irradiated with photons of energy equal to or greater than the forbidden band, the $\mathrm{e}^{-}$in the $\mathrm{VB}$ were excited and jumped to the $\mathrm{CB}$, with $\mathrm{h}^{+}$being generated in the $\mathrm{VB}$ to form $\mathrm{e}^{-} / \mathrm{h}^{+}$pairs. Because of the discontinuous region between the energy bands, the resulting $\mathrm{e}^{-} / \mathrm{h}^{+}$pairs had greater longevity; hence, they migrated to the particle surface in large quantities. The oxidizing properties of the nanoparticle surfaces were potent enough to oxidize the NPX molecules that were adsorbed to the $\gamma$-FeOOH surfaces. Additionally, the cavities reacted with $\mathrm{H}_{2} \mathrm{O}$ molecules, which were also attached to the surface of $\gamma-\mathrm{FeOOH}$, which then generated .OH. Due to the strong oxidization ability of $\cdot \mathrm{OH}$, the NPX molecules on the surface of $\gamma$-FeOOH could also be oxidized 

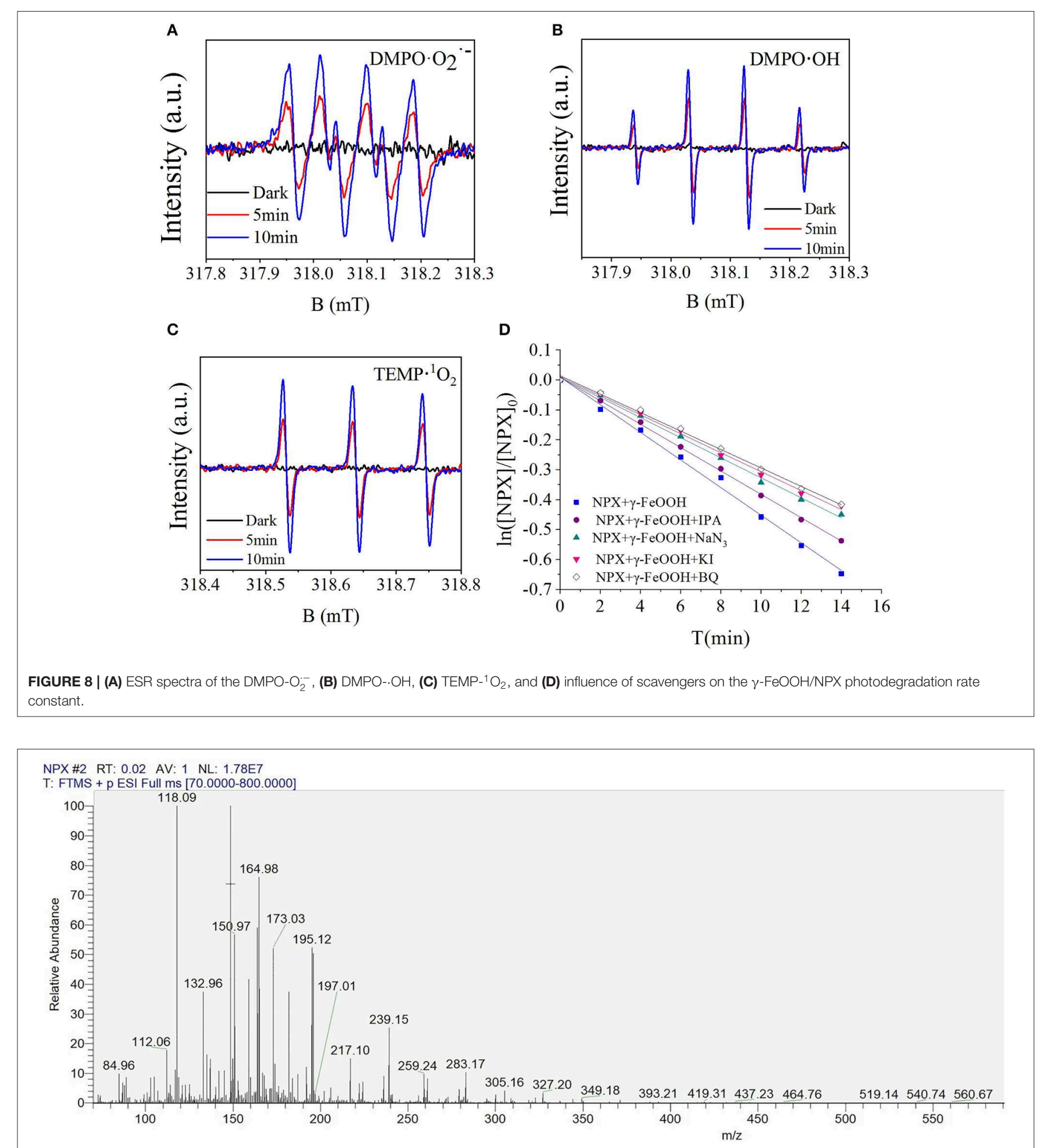

FIGURE 9 | HRLC-MS-MS spectrum of the intermediates on the $\gamma$-FeOOH/NPX system.

and degraded. Simultaneously, conducting electrons were combined with $\mathrm{O}_{2}$ at the surface of the $\gamma-\mathrm{FeOOH}$ to generate $\mathrm{O}_{2}^{--}$, which could also facilitate the oxidative degradation of NPX.
On the other hand, under sunlight exposure, Fe (III) could accelerate the oxidation of carboxylic acid. As NPX contains a carboxyl group, it could form strong complexes with $\mathrm{Fe}$ (III), which rapidly photochemically reacted under light 
irradiation (Zuo and Hoigne, 1992; Faust and Zepp, 1993), thereby accelerating the oxidative degradation of NPX. Several studies have suggested that the photochemical reaction of these complexes follows the $\mathrm{H}_{2} \mathrm{O}_{2}$ production process in water.

$$
\begin{array}{r}
\mathrm{Fe}\left(\mathrm{OX}_{\mathrm{n}}^{(3-2 \mathrm{n})+}\right)+\mathrm{hv} \rightarrow \mathrm{Fe}\left(\mathrm{OX}_{\mathrm{n}-1}^{(4-2 \mathrm{n})+}\right)+\mathrm{OX}^{-} \\
\mathrm{OX}^{-}+\mathrm{O}_{2} \rightarrow \mathrm{O}_{2}^{--}+2 \mathrm{CO}_{2} \\
\mathrm{O}_{2}^{\cdot-}+\mathrm{H}^{+} \rightarrow \mathrm{HO}_{2} \\
\mathrm{HO}_{2} / \mathrm{O}_{2}^{--}+\mathrm{Fe}(\mathrm{III})+\mathrm{H}^{+} \rightarrow \mathrm{Fe}(\mathrm{II})+\mathrm{O}_{2} \\
\mathrm{HO}_{2} / \mathrm{O}_{2}^{--}+\mathrm{Fe}(\mathrm{II})+\mathrm{H}^{+} \rightarrow \mathrm{Fe}(\mathrm{III})+\mathrm{H}_{2} \mathrm{O}_{2}
\end{array}
$$

For this photodegradation experiment, the effect of hydrokinetics must also be considered, as light exposure under stirring was first applied. With agitation, the mass transfer rate of NPX from the solution to the $\gamma-\mathrm{FeOOH}$ surface was increased, so additional NPX was oxidized prior to $\mathrm{e}^{-} / \mathrm{h}^{+}$recombination and thus the photodegradation of NPX was increased. Moreover, DO present in the solution could capture the photogenerated electrons generated during the photocatalytic process, which reduced the probability of the recombination of photogenerated electrons and holes, and thus increased the probability of holes oxidizing the NPX. When exposed to UV light, the $\mathrm{e}^{-}$at the surface of the $\gamma$-FeOOH could reduce $\mathrm{O}_{2}$ to $\mathrm{O}_{2}^{-}$, as shown in Equation (20). Subsequently, $\mathrm{O}_{2}^{--}$reacted with photogenerated holes $\mathrm{h}^{+}$to form $\cdot \mathrm{OH}$ or peroxide in the presence of organic capture agents, as in Equations (21)-(23). Each of these species contributed to the photodegradation of NPX.

$$
\begin{aligned}
\mathrm{e}^{-}+\mathrm{O}_{2} & \rightarrow \mathrm{O}_{2}^{--} \\
2 \mathrm{O}_{2}^{--}+2 \mathrm{H}^{+} & \rightarrow \mathrm{O}_{2}+\mathrm{H}_{2} \mathrm{O}_{2} \\
\mathrm{H}_{2} \mathrm{O}_{2}+\mathrm{e}^{-} & \rightarrow \mathrm{HO} \cdot+\mathrm{OH}^{-} \\
\mathrm{O}_{2}^{--}+\mathrm{NPX} & \rightarrow \mathrm{NPX}-\mathrm{OO}
\end{aligned}
$$

\section{Identification of Intermediates}

The degradation by-products of NPX on the $\gamma$-FeOOH /NPX system were identified by Thermo Scientific Ultimate 3000 RSLC and Q Exactive Orbitrap (HRLC-MS-MS). As shown in Figure 9, seven intermediates were detected. From attacked by $\mathrm{h}^{+}, \mathrm{e}^{-}$, $\cdot \mathrm{OH},{ }^{1} \mathrm{O}_{2}$, and $\mathrm{O}_{2}^{--}$, compounds were generated because of the losses of the $\mathrm{CO}_{2}, \mathrm{H}_{2} \mathrm{O}$, and/or $\mathrm{CH}_{3}$ group. According to the deduced structure of the compounds and the early study, we speculated the reasonable reaction approach as shown in Figure 10.

\section{CONCLUSIONS}

This study concludes that the photodegradation rate of NPX was positively correlated with the concentration of $\gamma$ $\mathrm{FeOOH}$ in solution, which was related to the absorption of light energy. With increased initial concentrations of NPX, the photodegradation rate decreased while the $\gamma$-FeOOH concentration was constant. This was because the population of photons available per NPX molecule was reduced due to the invariable intensity of light, and the numbers of $\mathrm{e}^{-} / \mathrm{h}+$ pairs generated on the surface of the $\gamma$-FeOOH were reduced per unit.

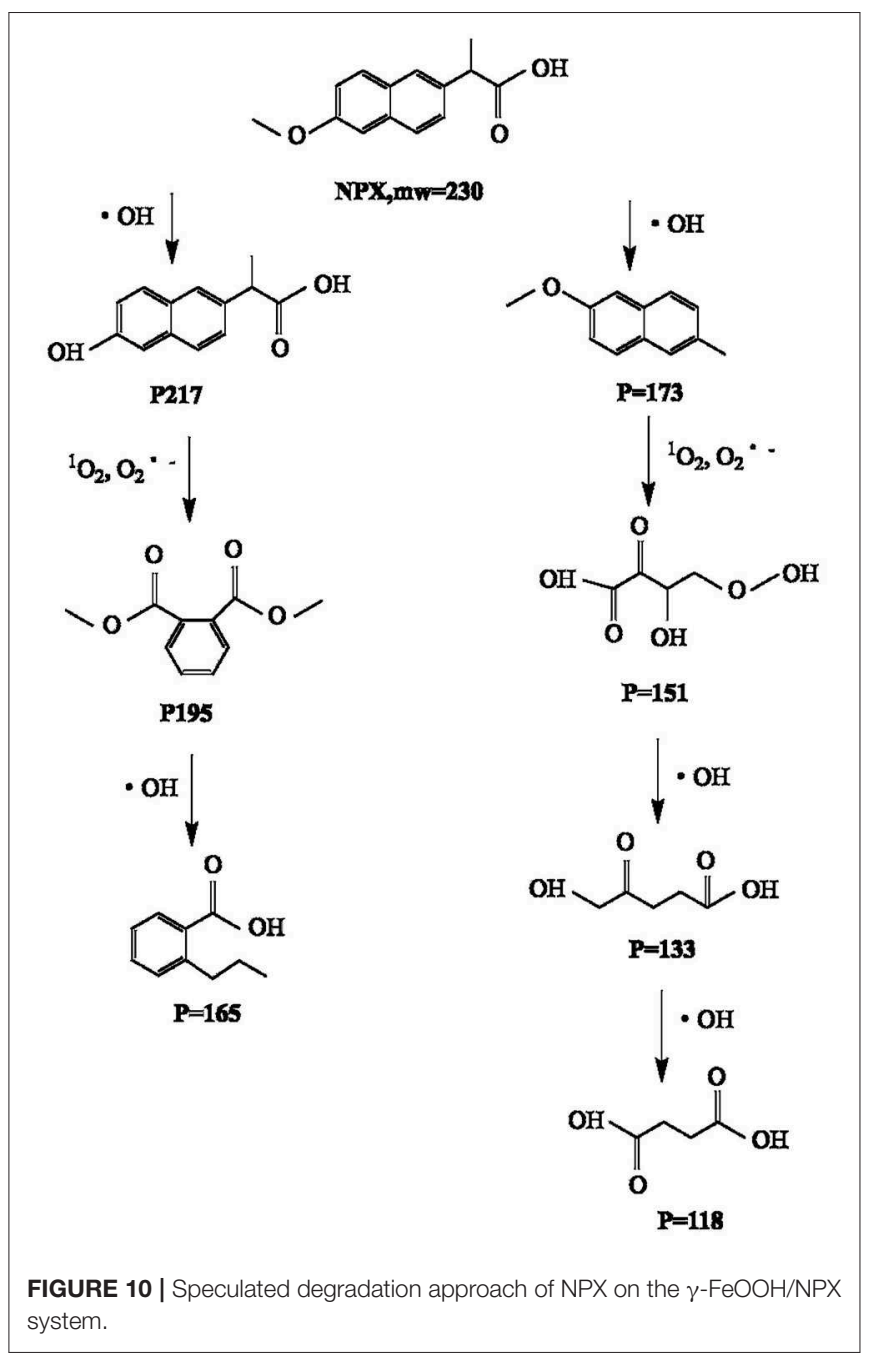

At the same time, the intermediate products generated by the reaction could not be completely decomposed in time, so they engaged in a reverse reaction to reconstitute the NPX matrix. At the tested $\mathrm{pH}$ values (5.0, 7.0, and 9.0), the photocatalytic rate was noticeably accelerated at higher and lower $\mathrm{pH}$, while the worst $\mathrm{pH}$ for photocatalysis was 7.0. Based on quenching experiments and analysis of the photocatalytic mechanism, we conclude that the photocatalysis of NPX degradation by $\gamma$-FeOOH is derived from semiconductor photocatalysis. At last, the intermediates of NPX on the $\gamma$-FeOOH /NPX System were identified by HRLC-MS-MS.

\section{DATA AVAILABILITY STATEMENT}

All datasets generated for this study are included in the manuscript.

\section{AUTHOR CONTRIBUTIONS}

ZL and GL formulated the problem and designed the experiments. ZL, XJ, and XW performed the experiments. ZL and 
QS took part in data collection and analysis and wrote the paper. QS and CL revised the manuscript.

\section{FUNDING}

This work was supported by National Natural Science Foundation of China (No. 21677040), Guangdong Provincial Science and Technology Planning Project of China (No.

\section{REFERENCES}

Alfano, O. M., Cabrera, M. I., and Cassano, A. E. (1997). Photocatalytic reactions involving hydroxyl radical attack. J. Catal. 172, 370-379. doi: 10.1006/jcat.1997.1858

Andreozzi, R., Caprio, V., and Marotta, R. (2003). Iron (III)(hydr) oxide-mediated photooxidation of 2-aminophenol in aqueous solution: a kinetic study. Water Res. 37, 3682-3688. doi: 10.1016/S0043-1354(03)00271-9

Bandana, J., Mielczarski, J., and Kiwi, J. (1999). Molecular mechanism of surface recognition. azo degradation on $\mathrm{Fe}, \mathrm{Ti}$, and $\mathrm{Al}$ oxides through metal sulfonate complexes. Langmuir15, 767-7679. doi: 10.1021/la9900270

Bandana, J., Mielczarski, J. A., Lopez, A., and Kiwi, J. (2001a). Sensitized degradation of chlorophenols on iron oxides induced by visible light : Comparison with titanium oxide. Appl. Catal. B Environ. 34, 321-333. doi: 10.1016/S0926-3373(01)00225-9

Bandana, J., Tennakone, K., and Kiwi, J. (2001b). Surface mechanism of molecular recognition between aminophenols and iron oxide surfaces. Langmuir 17, 3964-3969. doi: 10.1021/la001411w

Barnard, A. S., Zapol, P., and Curtiss, L. (2005). Anatase and ruble surface with adsobates representative of acidic and basic conditions. Surf. Sci. 582, 173-188. doi: 10.1016/j.susc.2005.03.014

Chen, Y. L., Liu, G. G., Yao, K., and Lü, W. (2013). Treatment of naproxencontaining water in low concentration by ultraviolet irradiation. Chin. J. Environ. Eng. 2, 473-476. Available online at: http://www.cjee.ac.cn/article/id/ 20130212

Christina, I. K., Dimitra, A. L., and Triantafyllos, A. A. (2014). Investigation of PPCPs in wastewater treatment plants in Greece: Occurrence, removal and environmental risk assessment. Sci. Total Environ. 466-467, 421-438. doi: 10.1016/j.scitotenv.2013.07.044

Dai, G., Huang, J., Chen, W., Wang, B., Yu, G., and Deng, S. (2014). Major pharmaceuticals and personal care products (PPCPs) in wastewater treatment plant and receiving water in Beijing, China, and associated ecological risks. $B$ Environ. Contam. Tox. 92, 655-661. doi: 10.1007/s00128-014-1247-0

Domínguez, J. R., González, T., Palo, P., and Cuerda-Correa, E. M. (2011). Removal of common pharmaceuticals present in surface waters by Amberlite XAD-7 acrylic-ester-resin: influence of $\mathrm{pH}$ and presence of other drugs. Desalination 269, 231-238.doi: 10.1016/j.desal.2010.10.065

Du, W., Xu, Y., and Wang, Y. (2008). Photoinduced degradation of orange II on different iron (hydr) oxides in aqueous suspension: rate enhancement on addition of hydrogen peroxide, silver nitrate, and sodium fluoride. Langmuir 24, 175-181. doi: 10.1021/la7021165

Farcasiu, M., Smith, C., Pradhan, V. R., and Wender, I. (1991). Iron compounds and iron catalysts: activity in reactions relevant to direct coal liquefaction. Fuel Process. Technol. 29, 199-208. doi: 10.1016/0378-3820(91)90036-C

Faust, B. C., and Hoffmann, M. R. (1986). Photoinduced reductive dissolution of a- $\mathrm{Fe}_{2} \mathrm{O}_{3}$ by bisulfate. Environ. Sci. Technol. 20, 943-948.

Faust, B. C., and Zepp, R. G. (1993). Photochemistry of aqueous iron (III)polycarboxylate complexes: roles in the chemistry of atmospheric and surface waters. Environ. Sci. Technol. 27, 2517-2522. doi: 10.1021/es00048a032

Fortin, D., and Langley, S. (2005). Formation and occurrence of biogenic iron- rich minerals. Earth Sci. Rev. 72. 1-19. doi: 10.1016/j.earscirev.2005.03.002

Galindo, C., Jacques, P., and Kalt, A. (2001). Photooxidation of the phenylazonaphthol $\mathrm{AO} 20$ on $\mathrm{TiO}_{2}$ : kinetic and mechanist investigations. Chemosphere 45, 997-1005. doi: 10.1016/S0045-6535(01)00118-7
2017A050506052), Zhejiang Provincial Natural Science Foundation of China (No. LY17F050001), and China Scholarship Council (No. [2018]5028).

\section{ACKNOWLEDGMENTS}

The authors would like to thank the reviewers and editors for their assistance toward the improvement of this paper.

Hao, R., Wang, G., and Tang, H. (2016). Template-free preparation of macro/mesoporous $\mathrm{g}-\mathrm{C}_{3} \mathrm{~N}_{4} / \mathrm{TiO}_{2}$ heterojunction photocatalysts with enhanced visible light photocatalytic activity. Appl. Catal. B Environ. 187, 47-58. doi: 10.1016/j.apcatb.2016.01.026

Hasan, Z., Jeon, J., and Jhung, S. H. (2012). Adsorptive removal of naproxen and clofibric acid from water using metal-organic frameworks. J. Hazard. Mater. 209-210, 151-157. doi: 10.1016/j.jhazmat.2012.01.005

He, Y. P., Miao, Y. M., Li, C. R., Wang, Q., Cao, L., Xie, S. S., et al. (2005). Size and structure effect on optical transitions of iron oxide nanocrystals. Phys. Rev. B. 71:125411. doi: 10.1103/physrevb.71.125411

Hoffmann, M. R., Martin, S. T., Choi, W., and Bahnemann, D. W. (1995). Environmental applications of semiconductor photocatalysis. Chem. Rev. 95, 69-96. doi: 10.1021/cr00033a004

Houas, A., Lachheb, H., Ksibi, M., Elaloui, E., Guillard, C., and Herrmann, J. M. (2001). Photocatalytic degradation pathway of methylene blue in water. Appl. Catal. B Environ. 31, 145-157. doi: 10.1016/S0926-3373(00) 00276-9

Isidori, M., Lavorgna, M., Nardelli, A., Parrella, A., Previtera, L., and Rubino, M. (2005). Ecotoxicity of naproxen and its phototrans formation products. Sci. Total Environ. 348, 93-101. doi: 10.1016/j.scitotenv.2004.12.068

Jones, O. A. H., Voulvorlis, N., and Lester, J. N. (2002). Aquatic environmental assessment of the top 25 English prescription pharmaceuticals. Water Res. 36, 5013-5022. doi: 10.1016/S0043-1354(02)00227-0

Karl, F., Anna, A. W., and Daniel, D. (2006). Ecotoxicology of human pharmaceuticals. Aquat. Toxicol. 76, 122-159. doi: 10.1016/j.aquatox.2005.09.009

Kruk, M., Jaroniec, M., and Sayari, A. (1997). Application of large pore MCM41 molecular sieves to improve pore size analysis using nitrogen adsorption measurements. Langmuir 13, 6267-6273. doi: 10.1021/la970776m

Lee, A. P., Brooker, L. R., Macey, D. J., van Bronswijk, W., and Webb, J. (2000). Apatite mineralization in teeth of the chiton acanthopleura echinata. Calc. Tissue Int. 67, 408-415. doi: 10.1007/s002230001156

Li, Y., Sun, S., Ma, M., Ouyang, Y., and Yan, W. (2008). Kinetic study and model of the photocatalytic degradation of rhodamine $\mathrm{B}(\mathrm{RhB})$ by a $\mathrm{TiO}_{2}$-coated activated carbon catalyst: effects of initial $\mathrm{RhB}$ content, light intensity and $\mathrm{TiO}_{2}$ content in the catalyst. Chem. Eng. J. 142, 147-155. doi: 10.1016/j.cej.2008.01.009

Ma, D. J., Liu, G. G., Lü, W. Y., Yao, K., Zhou, L. H., and Xie, C. P. (2013). Photodegradation of Naproxen in aqueous systems by UV irradiation: mechanism and toxicity of photolysis products. Environ. Sci. 34, 1782-1789. Available online at: http://www.hjkx.ac.cn/hjkx/ch/reader/view_abstract.aspx? flag=1\&file_no=20130517\&journal_id=hjkx

Méndez-Arriaga, F., Gimenez, J., and Esplugas, S. (2008). Photolysis and $\mathrm{TiO}_{2}$ photocatalytic treatment of naproxen: degradation, mineralization, intermediates and toxicity. J. Adv. Oxid. Technol. 3, 435-444. doi: 10.1515/jaots-2008-0302

Molgaard, J. (1974). "Corrosion of cast iron in chlorinated sea water," in 5th International Congress on Metallic Corrosion (Tokyo), 792-795.

Nurmi, J. T., Tratnyek, P. G., Sarathy, V., Baer, D. R., Amonette, J. E., Pecher, K., et al. (2005). Characterization and properties of metallic iron nanoparticles: Spectroscopy,electrochemistry, and kinetics. Environ. Sci. Technol. 39, 1221-1230. doi: 10.1021/es049190u

Pan, G., and Liss, P. S. (1998). Metastable-equilibrium adsorption theory: II. Experimental. J. Coll. Interface Sci. 201, 71-76. doi: 10.1006/jcis.1998.5397 
Turchi, C. S., and Ollis, D. F. (1990). Photocatalytic degradation of organic water contaminants: Mechanisms involving hydroxyl radical attack. J. Catal. 122, 178-192. doi: 10.1016/0021-9517(90)90269-P

Xu, J., Wu, L., and Chang, A. C. (2009). Degradation and adsorption of selected pharmaceuticals and personal care products (PPCPs) in agricultural soils. Chemosphere 77, 1299-1305. doi: 10.1016/j.chemosphere.2009.09.063

Zhang, N., Liu, G., Liu, H., Wang, Y., He, Z., and Wang, G. (2011). Diclofenac photodegradation under simulated sunlight: Effect of different forms of nitrogen and Kinetics. J. Hazard. Mater. 192, 411-418. doi: 10.1016/j.jhazmat.2011.05.038

Zhanyi, L., Guoguang, L., Qing, S., Jin, X., Wen, X., Zhang, G., et al. (2018). Kinetics and thermodynamics of NPX adsorption by $\gamma$-FeOOH in aqueous media. Arab. J. Chem. 11, 910-917. doi: 10.1016/j.arabjc.2018.02.005

Zheng, B. G., Niu, J. L., Zheng, Z., Zhang, J., Luo, X., Zhao, Y., et al. (2011). Catalytic degradation of Naproxen in aqueous solutions by gamma-ray irradiation. Environ. Chem. 12, 2022-2025. doi: 10.1007/s11783-010-0264-4

Zhou, S. G., Zhou, L. X., and Chen, F. X. (2007). Characterization and heavy metal adsorption properties of Schwertmannite synthesized by bacterial oxidation of ferrous sulfate solutions. Spectr. Spectr. Anal. 27, 367-370. doi: $10.1016 /$ j.sab.2007.02.003

Zuo, Y., and Hoigne, J. (1992). Formation of hydrogen peroxide and depletion of oxalic acid in atmospheric water by photolysis of iron (III)oxalato complexes. Environ. Sci. Technol. 26, 1014-1022. doi: 10.1021/ es00029a022

Conflict of Interest: The authors declare that the research was conducted in the absence of any commercial or financial relationships that could be construed as a potential conflict of interest.

Copyright (c) $2019 \mathrm{Li}, \mathrm{Liu}, \mathrm{Su}, \mathrm{Lv}$, Jin and Wen. This is an open-access article distributed under the terms of the Creative Commons Attribution License (CC BY). The use, distribution or reproduction in other forums is permitted, provided the original author(s) and the copyright owner(s) are credited and that the original publication in this journal is cited, in accordance with accepted academic practice. No use, distribution or reproduction is permitted which does not comply with these terms. 